\title{
Diagnosis of congenital cystic adenomatoid malformation of the lung in newborn infants and children
}

H A Heij, S Ekkelkamp, A Vos

\begin{abstract}
Seventeen patients were diagnosed as having congenital cystic adenomatoid malformation of the lung during 1970-88. One case was associated with congenital diaphragmatic hernia and the child died before operation. The other 16 children underwent successful surgery. The patients presented in one of three wayswith neonatal respiratory impairment (12 cases) requiring urgent diagnosis and treatment, with recurrent respiratory tract infections (3), and with pneumothorax (1). Diagnostic problems arose with the neonatal presentation. In four of the children laparotomy was performed for presumed diaphragmatic hernia; three of these children had right sided lesions. Congenital diaphragmatic hernia was excluded by contrast studies in a further two patients. Histological examination confirmed the diagnosis in all cases. The postoperative course was uneventful in all 16 patients. No long term impairment of pulmonary function was noted.
\end{abstract}

Congenital cystic adenomatoid malformation of the lung may cause severe respiratory problems in the newborn. Urgent diagnosis and operation are indicated to relieve the increased intrapleural pressure and mediastinal shift. At surgery excision of the lesion may be performed at leisure as soon as the affected part of the lung is brought outside the thorax. The long term prognosis after successful surgery is good. The diagnosis is often made by chest radiography, but differentiation from congenital diaphragmatic hernia may be difficult. A cystic adenomatoid malformation can be detected by antenatal ultrasound; this makes it possible to transfer the mother to a paediatric surgical centre before delivery. ${ }^{1}$

Cystic adenomatoid malformation sometimes leads to stillbirth with fetal hydrops. In addition to antenatal and neonatal problems, it may cause recurrent respiratory tract infections in later childhood.

We report our experience with 17 patients with congenital cystic adenomatoid malformation, 16 of whom had successful surgery. The various types of presentation and diagnostic problems are discussed.

\section{Patients and methods}

Since our previous report on seven cases of cystic adenomatoid malformation of the lung, ${ }^{2}$ 10 more patients have been diagnosed in our units-a total of 17 patients having presented from 1970 to 1988 . The table gives details of the patients. One premature baby of $730 \mathrm{~g}$, who also had a left sided congenital diaphragmatic hernia, died before operation. At necropsy cystic adenomatoid malformation of the right lower lobe was found, but was not thought to be a cause of death. ${ }^{3}$

Of the other 16 patients, 12 developed respiratory distress immediately after birth, three presented with (recurrent) respiratory tract infections at 2 weeks and 6 and 10 months
Department of Paediatric Surgery, Free University Hospital, and Emma Children's Hospital, Amsterdam, The Netherlands H A Heij S Ekkelkamp A Vos

Address for reprint requests: Dr H A Heii, Department of Paediatric Surgery, Free University Hospital, PO Box 7057, 1007 MB Amsterdam, The Netherlands.

Accepted 1 November 1989.
Details of 17 patients with congenital cystic adenomatoid malformation of the lung

\begin{tabular}{|c|c|c|c|c|c|c|}
\hline $\begin{array}{l}\text { Patient } \\
\text { No }\end{array}$ & Sex & Symptoms: since & Site & Operation & $\begin{array}{l}\text { Age at } \\
\text { operation }\end{array}$ & $\begin{array}{l}\text { Method of } \\
\text { diagnosis }\end{array}$ \\
\hline $\begin{array}{r}1 \\
2 \\
3 \\
4 \\
5 \\
6 \\
7 \\
8 \\
9 \\
10 \\
11 \\
12 \\
13\end{array}$ & $\begin{array}{l}F \\
F \\
M \\
M \\
F \\
M \\
M \\
F \\
M \\
M \\
M \\
M \\
M\end{array}$ & $\begin{array}{l}\text { Dyspnoea: birth } \\
\text { Dyspnoea: birth } \\
\text { Dyspnoea: birth } \\
\text { Dyspnoea: birth } \\
\text { Dyspnoea: birth } \\
\text { Dyspnoea: birth } \\
\text { Dyspnoea: } 2 \text { wk } \\
\text { Dyspnoea: birth } \\
\text { Dyspnoea: < } 3 \text { wk } \\
\text { Dyspnoea: birth } \\
\text { Dyspnoea: birth } \\
\text { Dyspnoea: birth } \\
\text { Dyspnoea: birth }\end{array}$ & $\begin{array}{l}\text { LLL } \\
\text { RML } \\
\text { LUL } \\
\text { RLL } \\
\text { LUL } \\
\text { RML } \\
\text { LUL } \\
\text { RUL } \\
\text { LLL } \\
\text { LLL } \\
\text { RLL } \\
\text { RLL } \\
\text { LUL }\end{array}$ & $\begin{array}{l}\text { Segment } \\
\text { Lobectomy } \\
\text { Lobectomy } \\
\text { Segment } \\
\text { Segment } \\
\text { Lobectomy } \\
\text { Lobectomy } \\
\text { Segment } \\
\text { Lobectomy } \\
\text { Lobectomy } \\
\text { Lobectomy } \\
\text { Lobectomy }\end{array}$ & $\begin{array}{l}1 \text { day } \\
1 \text { day } \\
8 \text { wk } \\
0 \text { day } \\
1 \text { day } \\
0 \text { day } \\
2 \text { wk } \\
4 \text { days } \\
6 \text { wk } \\
2 \text { days } \\
0 \text { day } \\
1 \text { day }\end{array}$ & $\begin{array}{l}1 \\
1,9 \\
1,2,3,4 \\
1 \\
1,6 \\
1,9 \\
1,7 \\
1 \\
1 \\
1,2 \\
1,8,9 \\
\text { Necropsy } \\
1\end{array}$ \\
\hline $\begin{array}{l}14 \\
15 \\
16\end{array}$ & $\begin{array}{l}\mathbf{M} \\
\mathbf{M} \\
\mathbf{F}\end{array}$ & $\begin{array}{l}\text { RTI: } 6 \mathrm{mo} \\
\text { RTI: } 1 \mathrm{wk} \\
\text { RTI: } 10 \mathrm{mo}\end{array}$ & $\begin{array}{l}\text { LUL } \\
\text { RLL } \\
\text { LUL }\end{array}$ & $\begin{array}{l}\text { Segment } \\
\text { Lobectomy } \\
\text { Lobectomy }\end{array}$ & $\begin{array}{l}4 \mathrm{y} \\
3 \mathrm{wk} \\
11 \mathrm{mo}\end{array}$ & $\begin{array}{l}1,2,3,4 \\
1,2,3,5\end{array}$ \\
\hline 17 & $\mathbf{M}$ & Pneumothorax: 12 y & LLL & Lobectomy & $12 \mathrm{y}$ & 1 \\
\hline
\end{tabular}

^1-Chest radiography; 2-bronchoscopy; 3-bronchography; 4-ventilation-perfusion scanning; 5-computed tomography; 6 - contrast upper gastrointestinal study; 7 - contrast enema; 8 - antenatal ultrasound; 9 -laparotomy.

RTI-respiratory tract infection; LL-lower lobe; ML-middle lobe; UL-upper lobe; L-left; R-right; segment-segmental RTI-respira
resection. 
Figure 1 Chest radiograph of a newborn infant with cystic adenomatoid malformation of the left lung, showing multiple cystic structures. The mediastinum is shifted towards the right and the left diaphragm is not visible.
Figure 2 Chest radiograph of a newborn infant with congenital diaphragmatic hernia on the left.
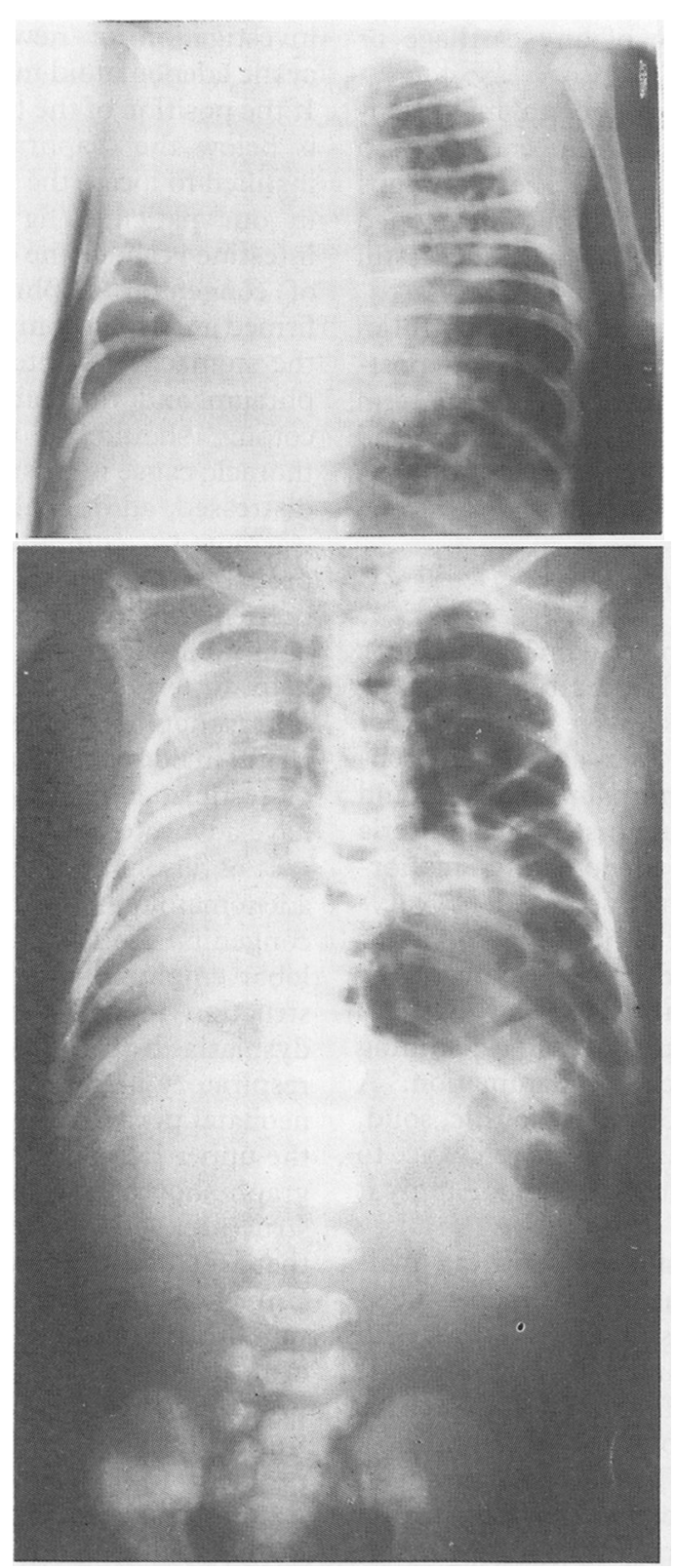

The malformations and their outcome

The differentiation between congenital cystic adenomatoid malformation and diaphragmatic hernia in newborn infants was a major diagnostic problem. Four babies had a laparatomy for the erroneous diagnosis of congenital diaphragmatic hernia, which in one case had been apparently established antenatally with ultrasonography. When an intact diaphragm was found at operation a thoracotomy was performed in the same session in all these patients. Three of them had right sided lesions. In two other patients doubt existed about the diagnosis of congenital diaphragmatic hernia; one had a contrast upper gastrointestinal study and the other a contrast enema to confirm the normal position of the intestine.

A final diagnosis of congenital cystic adenomatoid malformation was confirmed by histological criteria-namely, the presence of cystic structures of varying size, with an epithelial lining arranged in adenomatoid
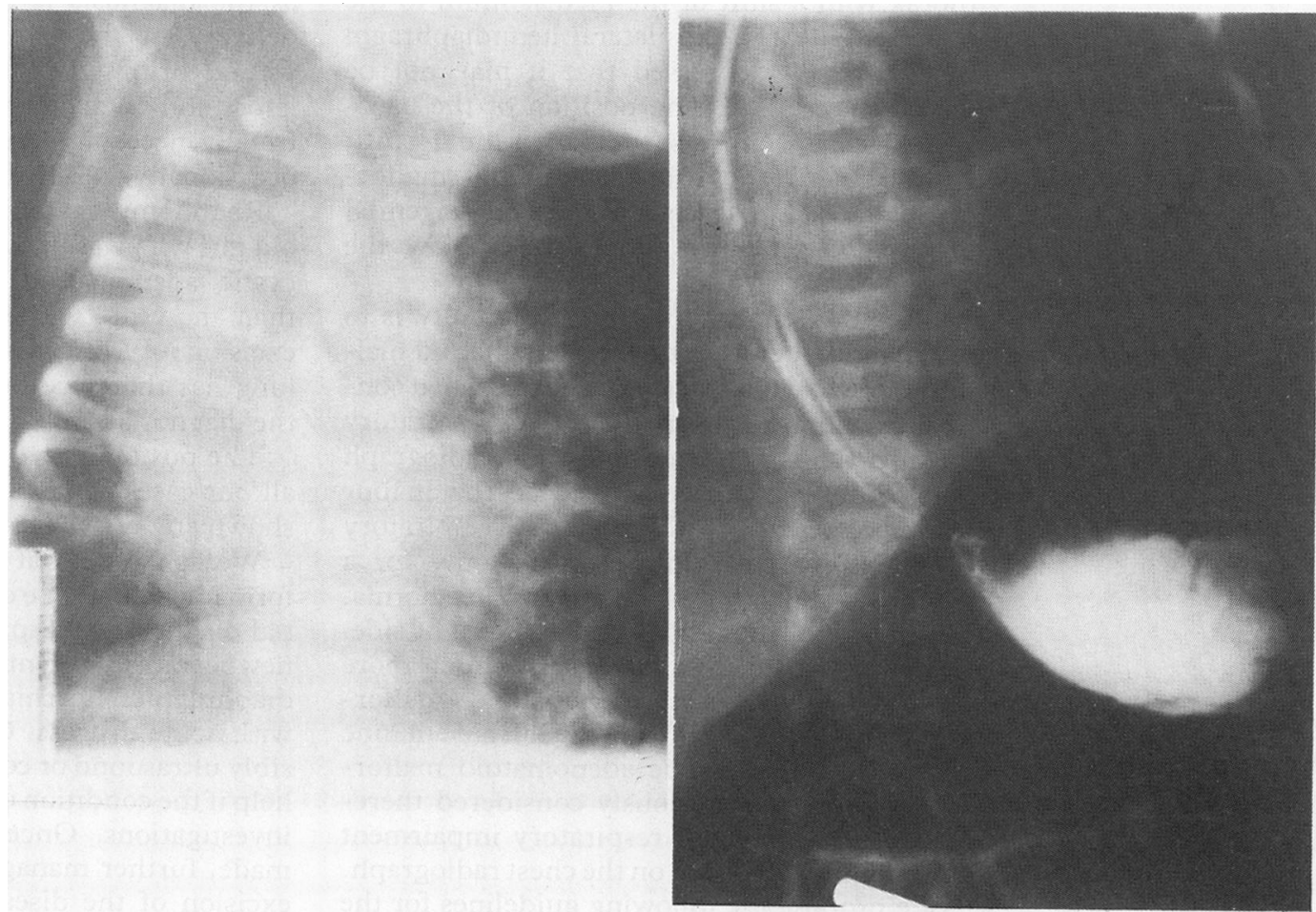

respectively, and one patient presented with wo children were born at term and had a out of 17-were located on the left side, six in upper lobe and four in the lower lobe. Of obe and two in the middle lobe.

malformation was made by chest radiography alone in seven cases. In four patients bronchoabnormalities except for some displacement of perfusion scanning showed a perfusion defect of the left upper lobe.
The figures are reproduced from Vos and Ekkelkamp ${ }^{2}$ by courtesy of Hippocrates Verlag.
Figure 3 Barium swallow from the patient whose radiograph is shown in figure 1. The stomach is confirming the diagnosis congenital cystic adenomatoid malformation.

Pdy


patterns, in the absence of any cartilage or inflammation. ${ }^{5}$

There were additional congenital malformations in some of these children: one boy also had a congenital diaphragmatic hernia; a girl had a split hand deformity; and a boy developed hydrocephalus, for which he had successful shunt surgery.

The postoperative course was uneventful in all 16 cases. The mean duration of postoperative hospital stay was 10 days. Long term pulmonary function is good in all children and we have not seen any spinal deformities as a result of the neonatal thoracotomy.

\section{Discussion}

Congenital cystic adenomatoid malformation is considered to be a local aberration of parenchymal tissue with an excessive overgrowth of bronchioli that fail to join alveolar mesenchyma. ${ }^{67}$ The older term, hamartoma, should be avoided. The following histological criteria for congenital cystic adenomatoid malformation have been generally accepted: (1) varying sized cysts, lined by cuboidal to columnar epithelium; (2) polypoid configuration of the mucosa of the cysts; (3) absence of cartilage; (4) presence of a group of mucogenic cells lining the cyst wall; (5) absence of inflammation. ${ }^{5} \mathrm{~A}$ distinction is often made between cystic, solid, and intermediate lesions; but as its relevance to clinical practice is not clear we did not apply it to our cases.

The diagnosis of cystic adenomatoid malformation should be suspected when a newborn infant develops respiratory distress with diminished breath sounds on one side. It should be noted whether the abdomen is scaphoid, as this may point to the diagnosis of diaphragmatic hernia. The chest radiograph in congenital cystic adenomatoid malformation shows multiple cystic structures in one hemithorax with a shift of the mediastinum to the opposite side. The ipsilateral hemidiaphragm is so severely depressed that it may not be discernible (fig 1). The position of the nasogastric tube confirms the mediastinal shift; with congenital cystic adenomatoid malformation (in contrast to some cases of congenital diaphragmatic hernia) the tip is below the diaphragm.

In clinical practice the main difficulty is to differentiate between cystic adenomatoid malformation and diaphragmatic hernia when confronted with a newborn infant with respiratory impairment and an abnormal chest radiograph (fig 2). This is illustrated by the fact that in four of our patients with neonatal respiratory problems we performed a laparotomy for a presumed diagnosis of diaphragmatic hernia. In three cases the lesion was on the right side. Diaphragmatic hernia is not only much more common than cystic adenomatoid malformation but it also occurs on the left side in nine out of 10 cases. Cystic adenomatoid malformation should be seriously considered therefore in neonates with respiratory impairment and a right sided lesion on the chest radiograph.

We propose the following guidelines for the investigation of newborn infants in whom cystic adenomatoid malformation is suspected. If the position of the tip of the nasogastric tube is below the diaphragm, contrast should be instilled to locate the intestine, as we did twice in our patients (fig 3). If the stomach or intestine is above the diaphragm, the diagnosis of congenital diaphragmatic hernia is confirmed and laparotomy should be performed. If the stomach and intestine are below the diaphragm and the baby is in distress, thoracotomy should be performed as an intrathoracic cause is most likely. If the child is not distressed, additional diagnostic measures are warranted, computed tomography being probably the most helpful. Bronchoscopy, bronchography, and radionuclide scanning are of limited value in our experience, but they may help to exclude other pulmonary diseases. Ultrasonography has been reported to be useful in both antenatal and postnatal diagnosis of cystic adenomatoid malformation. ${ }^{18}$ Others have advocated angiography. ${ }^{5}$

It is also important to differentiate cystic adenomatoid malformation from various other congenital thoracic malformations. Congenital lobar emphysema is caused by bronchial obstruction in half the cases, and by alveolar dysplasia in the other half. ${ }^{9}$ It may also cause respiratory impairment by air trapping in the neonatal period. It is almost always located in the upper lobes of the lungs. The chest radiograph shows hyperlucency rather than cystic structures. The management is identical to that of cystic adenomatoid malformation. Bronchogenic cyst and pulmonary sequestration are abnormalities of ventral foregut budding and originate either from the tracheobronchial tree or from the gastrointestinal tract. They do not usually cause acute problems in the newborn. ${ }^{6}$

The treatment of congenital cystic adenomatoid malformation is always surgical as soon as the diagnosis is made. Thoracotomy and delivery of the hyperinflated lobe into the wound brings immediate relief of the ventilatory and circulatory problems. Lobectomy is usually necessary, but segmental resection is occasionally feasible. ${ }^{10}$

Rhabdomyosarcoma was reported in a 2 year old girl who was known to have had congenital cystic adenomatoid malformation for more than a year without symptoms. Elective excision of congenital malformations of the lung has therefore been advocated as soon as the diagnosis is made. ${ }^{11}$

The postoperative course was uneventful in all our cases and long term follow up has not shown any restriction of pulmonary function.

We conclude that cystic adenomatoid malformation should be considered in the differential diagnosis of respiratory impairment in the newborn. Differentiation from congenital diaphragmatic hernia may be difficult in those with acute distress. Contrast studies and possibly ultrasound or computed tomography may help if the condition of the infant allows further investigations. Once the diagnosis has been made, further management is straightforward excision of the diseased portion of the lung. 
Prognosis, both short and long term, is excellent.

1 Adzick NS, Harrison MR, Glick PL, et al. Adenomatoid Malformation: prenatal diagnosis and natural history. $J$ Pediatr Surg 1985;20:483-8.

2 Vos A, Ekkelkamp S. Congenital cystic adenomatoid malformation of the lung in the newborn. $Z$ Kinderchir 1979;27: 125-30.

3 Ekkelkamp S, Vos A. A Newborn with congenital diaphragmatic hernia and congenital adenomatoid malformation of the lung. $Z$ Kinderchir 1980;28:65-7.

4 Ekkelkamp S, Vos A. Congenital cystic adenomatoid malformation of the lung: an unusual presentation. $Z$ Kinderchir 1987;42:253-4.

5 Miller RK, Sieber WK, Yunis EJ. Congenital adenomatoid malformation of the lung. Pathol Annu 1980;15:387-406. 6 Rodgers BM, Harman PK, Johnson AM. Bronchopulmonary foregut malformation. Ann Surg 1986;203:517-24.

7 Ryckman FC, Rosenkrantz JG. Thoracic surgical problems in infancy and childhood. Surg Clin N Am 1985;65: in infancy

8 Hartenberg MA, Brewer WH. Cystic adenomatoid malformation of the lung: identification by sonography. AJR 1983;140:693-4.

9 Lorimier AA de. Congenital malformations and neonatal problems of the respiratory tract. In: Welch KJ, Randolph JG, Ravitch MM, O'Neill JA Jr, Rowe MI, eds. Pediatric surgery. Chicago: Yearbook Medical Publishers, 1986 $631-45$.

10 Nishibayashi SW, Andrassy RJ, Woolley MW. Congenita cystic adenomatoid malformation: a 30-year experience. $J$ Pediatr Surg 1981;16:704-6.

11 Ueda K, Gruppo R, Unger F, Martin L, Bove K. Rhabdomyosarcoma of lung arising in congenital cystic adenomyosarcoma of lung arising in congenital cystic 